\title{
TENTO\& CONTEXTO
}

TEXT \& CONTEXT NURSING TEXTO \& CONTEXTO ENFERMERÍA

\section{SYSTEMATIC REVIEW OF MIXED \\ METHODS: METHOD OF RESEARCH FOR THE INCORPORATION OF EVIDENCE IN NURSING}

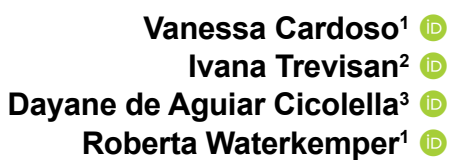

Roberta Waterkemper ${ }^{1}$ (D)

\begin{abstract}
Objective: to describe some methodological considerations on the Systematic Review of Mixed Methods developed by the Joanna Briggs Institute, seeking to disseminate the use of this methodology, exemplifying its use and demonstrating the benefits for nursing research.

Method: it is an article of reflection.

Result: it can be seen that the Systematic Review of Mixed Methods demonstrates that it is a research method that aligns with the characteristics of nursing care, making it possible to make a broader analysis of the different aspects of care such as: the viability of an activity or intervention, its adequacy to a specific context, the significance of the intervention for the patient and their effectiveness.

Conclusion: the possibility of incorporating scientific evidence into the clinical practice by the decision making, increasing the focus of care and bringing benefits to the patients as well as the public policies is envisaged. This method values the context of care, cost-effectiveness and the preferences of patients, caregivers and health care providers.
\end{abstract}

DESCRIPTORS: Nursing. Evidence-based clinical practice. Systematic review. Method. Methodology. 


\section{REVISÃO SISTEMÁTICA DE MÉTODOS MISTOS: MÉTODO DE PESQUISA PARA A INCORPORAÇÃO DE EVIDÊNCIAS NA ENFERMAGEM}

\section{RESUMO}

Objetivo: descrever algumas considerações metodológicas sobre a Revisão Sistemática de Métodos Mistos desenvolvida pelo Instituto Joanna Briggs, buscando divulgar o uso desta metodologia, exemplificando sua utilização e demonstrando os benefícios para a pesquisa em enfermagem.

Método: trata-se de um artigo de reflexão.

Resultado: percebe-se que a Revisão Sistemática de Métodos Mistos demonstra ser um método de pesquisa que se alinha às características do cuidado em enfermagem, possibilitando fazer uma análise mais ampla dos diferentes aspectos do cuidado como: a viabilidade de uma atividade ou intervenção, sua adequação a um determinado contexto, a significância da intervenção para o paciente e a sua eficácia.

Conclusão: vislumbra-se a possibilidade de incorporar evidências científicas à prática clínica pela tomada de decisão, ampliando o foco de cuidado e trazendo benefícios aos pacientes bem como às políticas públicas. Este método valoriza o contexto da prestação de cuidados, a relação custoeficácia, e as preferências dos pacientes, cuidadores e provedores de cuidados de saúde.

DESCRITORES: Enfermagem. Prática clínica baseada em evidências. Revisão Sistemática. Método. Metodologia.

\section{REVISIÓN SISTEMÁTICA DE MÉTODOS MISTOS: MÉTODO DE INVESTIGACIÓN PARA LA INCORPORACIÓN DE EVIDENCIAS EN LA ENFERMERÍA}

\section{RESUMEN}

Objetivo: describir algunas consideraciones metodológicas sobre la Revisión Sistemática de Métodos Mixtos desarrollada por el Instituto Joanna Briggs, buscando divulgar el uso de esta metodología, ejemplificando su utilización y demostrando los beneficios para la investigación en enfermería.

Método: se trata de un artículo de reflexión.

Resultados: se observa que la Revisión Sistemática de Métodos Mixtos demuestra ser un método de investigación que se alinea a las características del cuidado en enfermería, posibilitando hacer un análisis más amplio de los diferentes aspectos del cuidado como: la viabilidad de una evaluación actividad o intervención, su adecuación a un determinado contexto, la significancia de la intervención para el paciente y su eficacia.

Conclusión: se vislumbra la posibilidad de incorporar evidencias científicas a la práctica clínica por la toma de decisión, ampliando el foco de cuidado y aportando beneficios a los pacientes y a las políticas públicas. Este método valora el contexto de la atención, la relación costo-eficacia, así como las preferencias de los pacientes, cuidadores y proveedores de atención de salud.

DESCRIPTORES: Enfermería. Práctica clínica basada en evidencias. Revisión sistemática. Método. Metodología. 


\section{INTRODUCTION}

Nursing care is the result of complex interventions par excellence and plays an important role in health as it is carried out in various contexts and populations and accompanies socioeconomic, political and technological changes. Nurses increasingly occupy a broad field of complex activities, many of which occur in multi-care settings such as clinical units, chronic care units, community, longterm care facilities, home care, emergency medical care and even in disasters, not only in Brazil, but also in other countries. These activities place health care under the management of nurses, in most cases, increasing the scope and general need for nursing care.

Thus, for this care to be based on a solid evidence base, it is indisputable the need for nurses to search for scientific knowledge and the association of their clinical expertise as decision-making tools. In this scenario, the development of research methods that enable an Evidence-Based Practice (EBP) in real effective and change-multiplying nursing should be discussed. The discussion is a way of encouraging reflection on the use of research results in health care, considering the different levels of attention and complexity of care. It is known that the quantity and complexity of information in the health area have determined the need to develop processes that provide concise paths to the results of research. In EBP, among the research methods considered as gold standard in terms of a higher level of evidence, Systematic Reviews stand out. These are characterized as a modality of review of primary studies and gray literature* carried out to summarize scientific evidence that seeks to answer a specific research question and follow strict protocols to reduce bias and show the best evidence. ${ }^{1}$

Within the methods of Systematic Review, there is the modality of Mixed Methods of Research. In a simplified definition, it translates as a review that uses the findings of qualitative and quantitative studies, integrating qualitative and quantitative methods of analysis into the same research. ${ }^{2-3}$ This methodology works with a more comprehensive analysis, allowing to evaluate not only the effectiveness of the interventions, but also their viability, the adequacy of the intervention to a certain context, as well as the significance of the intervention for the patient and the economic aspects. ${ }^{3-4}$ However, we are aware of authors who defend the idea that a large part of health studies, which do not deal with the efficiency and efficacy of interventions focused and based on randomized studies, is not characterized as a systematic review. ${ }^{5}$ This thinking departs from Sackett's original purpose when he began his analysis of what is and is not evidence, demonstrating ways of thinking that remain "in the box." On the other hand, other authors, for many years, have presented conceptions and researches on health that allow to widen the look on the scientific evidence from complex problems, with the use of the Systematic Review, as in meta-ethnography, as well as other forms of synthesis. ${ }^{6-7}$ However, only recently has there been an increase in the use of systematic review approaches to answer other types of research questions. Criticism of this type of method, whether in Evidence-Based Medicine (MBE) or otherwise, is numerous, strong, and divergent. ${ }^{8}$ It should be stressed that this paper does not seek to make this discussion, but to present other possibilities of using the methodology, mainly to answer complex questions at different levels for nursing research.

Considering the importance of this association to improve health interventions, EBP was introduced in the mid-nineteenth century by David L. Sackett. ${ }^{9}$ By proposing the use of the best available evidence to facilitate clinical decision-making in the health area, not only thinking about the problem, but also the reconceptualization of complex problems, the EBP allows narrowing the gap between research, care practice and quality of life. care and safety of the patient. ${ }^{10-11}$ The author considers it as a self-directed lifelong learning process in which patient care creates the need for clinically important information on diagnosis, prognosis, therapy, and other clinical and health issues. ${ }^{12}$

\footnotetext{
* Gray literature (gray literature), according to the Cochrane Center, is understood as literature that is not formally published in sources such as books or periodicals. E.g.: conference summaries.
} 
The original thinking of its founder integrates with the essence of nursing care, and the EBP, in its context, emerges as a decision-making possibility in the daily care of nurses, on the health care of individuals or groups of patients based on the most relevant evidences, while not including their expectations, as well as those of society. ${ }^{13}$

Another strand that follows the EBP line, and which is in evidence today, is the translational research, (in the original, translational research), especially when the focus is on health innovation. ${ }^{14}$ It is noticed that there was a significant evolution in the quality of the clinical researches with the EBP, and it is questioned how its results are actually being applied in the resolution of health problems and in the transformation of the practice. This concern is the focus of translational research. ${ }^{11}$ Nursing, being the center of the health care of the population, whose essence of its investigations is the transformation of practice, has been contributing increasingly to the EBP, although its origin goes back to medicine. The literature highlights the important role of this science in interdisciplinary relationships and research and in the leadership of nurses in the field of translational research. ${ }^{14}$

Currently, since the understanding about the method of investigation presents varied interpretations and proposals for its development, there are numerous authors and groups of studies and researches that discuss and write on this subject. The Cochrane Center, founded by Sackett in 1994, is now characterized as an independent global network of researchers, practitioners, patients, caregivers and people interested in health. It is responsible for conducting systematic reviews with methodology and software to present the best scientific evidence available worldwide. This center is used in the health area as a reference in the development of this methodology, since it seeks to gather all the evidence that may fit the pre-specified eligibility criteria and related to a specific research question. This criterion aims to minimize bias and achieve more reliable results. By having its own methodology, it allows publication in the Cochrane Database of Systematic Reviews of the The Cochrane Library, provided that the methodology is used in accordance with its manuals. Among the reviews carried out by the Center are the systematic reviews with and without meta-analysis. In the meta-analysis statistical methods are used to summarize the results of independent studies. It is a methodology that focuses mainly on quantitative studies, although in other chapters it has manuals on review studies, including non-randomized studies, adverse effects, economic studies, patient reports, reviews with individual patient information, qualitative studies and studies involving aspects of health promotion. ${ }^{15}$ Therefore, in 1995, following the same purpose as Cochrane, the Center for Evidence-Based Medicine of the University of Oxford also had the influence of David L. Sackett, becoming one of the main references for the EBP, mainly for the evaluation of the level of evidence. In Brazil, in addition to these centers of reference, another source used for systematic review is the Department of Science and Technology (Decit), linked to the Ministry of Health. This department developed methodological guidelines for the elaboration of a systematic review based on the guidelines of Crochrane and the Australian Medical Research Council, but also focusing on quantitative approach, especially meta-analyzes of randomized clinical trials. ${ }^{1}$

It is believed that, due to the essence and complexity of nursing care, concepts and paradigms that still limit this care to a single strand of thought and research are needed. In this article, we describe some methodological considerations about the method of Systematic Review of Mixed Methods, seeking to disseminate the use of the methodology, exemplifying its use and reflecting on research possibilities for nursing research.

To exemplify the use of the methodology of Systematic Review of Mixed Methods in nursing, the article Strategies to promote coping and resilience in oncology and palliative care nurses caring for adult patients with malignancy: a comprehensive systematic review. ${ }^{16}$ This review aimed to identify individual search and organizational strategies for coping and resilience in oncology and palliative care of nurse caregivers of adult patients with malignant disease. The search strategy was based on 12 
databases, from 2007 to 2013, considering studies with qualitative, quantitative and mixed methods These clinical studies approach on employment supervision, personal retreats, psycho-educational programs, resilience programs, fatigue of compassion, stress and individual approaches that reduce the emotional impact of cancer care work. To evaluate the methodological quality of the studies, standardized critical evaluation instruments, developed by Joanna Briggs Institute (JBI). Nineteen studies were included in the review: ten studies examined the nurse's experience in caring, the emotional impact of palliative care and oncology, preventive work and strategies for avoiding exhaustion or fatigue, selfcare challenges, and coping processes with stress at work; six studies evaluated different interventions provided by organizations to improve coping and resilience; and evidence for the effectiveness of interventions was limited to three studies. The results are discussed in four categories: preventive measures, control measures, dismissal and professional growth. This evaluation identified a number of strategies to prepare nurses to practice and maintain their psychological well-being, although they have not made definitive conclusions about the most effective interventions. As an implication to the practice, the author describes the need for formal and informal support to promote coping strategies and resilience. By means of this study, the applicability of the method to the nursing is perceived. ${ }^{16}$

\section{THE METHODOLOGICAL APPROACH OF SYSTEMATIC REVIEW OF MIXED METHODS: SOME CONSIDERATIONS}

When thinking about health, today and in its history, it is possible to perceive the diverse origins and degrees of complexity of its problems. By such a characteristic, a growing diversity of research methodologies is required that enable the attainment of its objectives and add an eclectic enough character to incorporate classical, medical and scientific drawings, as well as the emergent qualitative research oriented to the action. ${ }^{4,17}$ In this context, it is not possible to think a particular synthesis is better than another. This is a linear and reductionist thinking that is incompatible with the transformations in the health area and the complexity of care for the population. ${ }^{17}$ This situation warns us that we must realize that adding research methods that allow the understanding and analysis of phenomena becomes more appropriate to this complexity. There is no right or wrong method, but goals and study needs of different phenomena.

Mixed method reviews attempt to maximize the results and the ability of these findings to bring information that can impact policy and practice. Its use is still emerging, and although there is a growing literature on these revisions, which include synthesis of quantitative and qualitative data, they are rarely combined in a single synthesis or in a secondary final synthesis. Most of the published articles develop synthesis based on themes derived from qualitative studies and incorporate quantitative data or analyze the qualitative and quantitative characteristics separately to then provide a brief narrative, discussing the results in general. ${ }^{4,17}$

The literature presents some aspects that approach concepts, definitions and descriptions on the Systematic Review of Mixed Methods. Among the authors with the highest representation in this medium are Ray Pawson, with the revision method based on the realistic synthesis, and Margaret Sandelowski and Jamie L. Crandell, with the revision method based on the Bayesian method. The common characteristic among authors and their affiliates is the concern with the incorporation of evidence that may characterize the context, the perception about the need for deconstruction and reconstruction of concepts related to EBP, and the real impact they cause in the change of public policies and population health. One thought to "what really works?"; $2-4,18$ and nothing more consistent with the research carried out in the field of nursing that seek change in the practice scenarios.

However, it is a consensus among the authors that the elaboration of a systematic review of relevant methods that can guide the implementation of effective interventions in health care must follow 
some clearly described principles and stages. In this study, we present the development proposal of Margaret Sandelowski and Jamie L Crandell, based on the Bayesian method adopted by JBI.

\section{The method}

The Bayesian method of data analysis can be defined to summarize uncertainties and make estimates and predictions using probabilistic statements conditioned by the observation of data in an assumed model..$^{19}$ It uses the metaaggregation, a method of synthesis of qualitative data developed by a group of researchers of this area, under the influence of Edmund Husserl. These, although agreeing to discuss a technique for qualitative syntheses, understood that qualitative literature should not be synthesized. They persisted in the search and eventually concluded that an approach consistent with the method of systematic review, not only the interpretive analysis of methods, could be developed and incorporated philosophical traditions of critical and interpretive paradigms and also promote qualitative concepts related to confidentiality, credibility and transferability. In other words, a valid and reliable approach to a systematic review, which should result in appropriate decision making. ${ }^{20} \mathrm{In}$ this way, this method allows the conversion of quantitative data into qualitative data and vice versa, in the same synthesis. However, for this to occur, both data need to be transformed into a compatible and egalitarian format, that is, translated into quantitative and qualitative data. ${ }^{4}$

There are two forms of conversion that can be performed, depending on the purpose of the study: conversion of qualitative data into quantitative data, or vice versa. In the first option, numerical values compatible with quantitative data are attributed, allowing the researcher to evaluate the quantitative of participants that represent a particular finding. Both data may or may not be analyzed independently in the same final synthesis, depending on the probability estimates reached in terms of credibility. The use of this option, according to the JBI, may present difficulties in the interpretation by word counting, considering that the qualitative data work with thematic and interpretative approaches and, therefore, difficult to be quantified. In the second option, similar variables are grouped into themes, and then each variable is encoded. ${ }^{4}$

Although JBl's Systematic Review of Mixed Methods is based on this method, for the conversion of raw quantitative data into qualitative subjects in order to generate a single combined synthesis, the JBI method applies the conversion process to the results of the individual syntheses, producing a single comprehensive synthesis that aggregates the results of the separate syntheses. ${ }^{4,21}$ Regardless of the quantitative data presented, as well as the derivation of defined themes and the codification of quantitative data, it is understood that this proposal of analysis shows to be less prone to the assignment of numerical values for qualitative data. By using quantitative and qualitative data to develop themes, and then coding all data into a compatible system for meta-aggregation analysis, we achieve an equal use of the two data sources. It is considered a more simplistic, elegant and yet with a power of fidelity, to work with the separated syntheses, a characteristic that is lost with a pre-synthesis. ${ }^{4}$

The results or evidence can be divided into two categories: quantitative and qualitative; of the findings, may support each other (confirmation) or contradict (refutation), as well as simply add one another (complementary). And, in this case, the category is not chosen by the reviewer: if the result of the study. ${ }^{4}$

To maintain rigor in the development of this method, JBI has as its principle that the researcher needs to file their interests, personal experiences, beliefs, and values in the way they look at the data and interpret them, and make sure that the whole context has been included from the reliable extraction of results from both quantitative and qualitative studies (it is the process of contextualizing the text - text in context/text in context The concern with the context of studies derived from methods with different characteristics is given by Sandelowisky's belief about the construction of the studies and the contexts in which they were constructed. Therefore, it uses the term text in context to speak 
of the need to describe the contexts in which the results were produced. The author understands that the results generated are not isolated from the methods used to reach them. ${ }^{2}$ This perception about research is in line with what Nursing, by its essence, has always been concerned with the context of vital processes, health, disease, education and care management.

\section{Stages of the Systematic Review of Mixed Methods}

The planning of the systematic review begins with the construction of the protocol. This section details the methodological steps that will be followed to reduce the risk of bias, as well as the transparency of the methods and processes adopted. The first step in the development of a systematic review of mixed methods, like any systematic review, is part of a research question. However, because of its characteristic of involving both qualitative and quantitative studies to result in a single synthesis, then, it requires two questions oriented to different phenomena. The construction of the research question is carried out by means of the acronyms PICO (Population, Intervention, Comparison and Results), for quantitative studies, and PICo (Population, Interest / phenomenon of interest and Context), for qualitative studies 4 (Box 1). The question posed is that it will determine the components of the review.

Box 1 - Examples of research questions using the PICO and PICo strategy

\begin{tabular}{|ll} 
PICo & $\begin{array}{l}\text { What are the experiences of nursing students about problem-based learning } \\
\text { at undergraduate level? }\end{array}$ \\
PICO & $\begin{array}{l}\text { Is problem-based learning more effective than non-arts pedagogy for } \\
\text { developing competencies and learning behaviors in nursing undergraduates? }\end{array}$
\end{tabular}

Source: adapted from JBI, 2014. ${ }^{4}$

With the research question defined, we start with the development of the revision protocol, which should be organized considering two revisions: one quantitative and the other, qualitative. Thus, for each item of the review, one should describe how each one will be developed according to the design, including inclusion criteria: type of participants, type of intervention / phenomenon of interest, type of studies, search strategy, methodological quality assessment, extraction and data analysis, according to ; 1 .

In addition to studies with a qualitative and quantitative design, JBI makes it possible to carry out revisions that focus on cost analysis, technology, use, evaluation and review of instruments. For each stage of the review, there are own tools to manage, evaluate, extract and synthesize the results of scientific evidence, in print form and through softwares such as Qualitative Assessment and Review Instrument (JBI-QARI) for qualitative studies; Meta-Analysis of Statistics Assessment and Review Instrument (JBI-MAStARI) for quantitative studies; Analysis of Cost, Technology and Utilization Assessment and Review Instrument (ACTUARI) for cost, technology and use, evaluation and review of instruments. ${ }^{4}$

The data extraction should specify information that may answer the specific research question and the objectives of the Joint Methods Review. For the qualitative research question, one should prioritize the description of the phenomenon of interest, population, methods, results and study findings. For the quantitative research question, details on interventions, population, method and results should be specified. ${ }^{4}$

The synthesis process is configured at the moment of the generation of affirmations that can represent the aggregation. For the qualitative studies, meta-synthesis is performed to produce a comprehensive synthesis of the findings and that can be used as a basis for EBP. This process is 


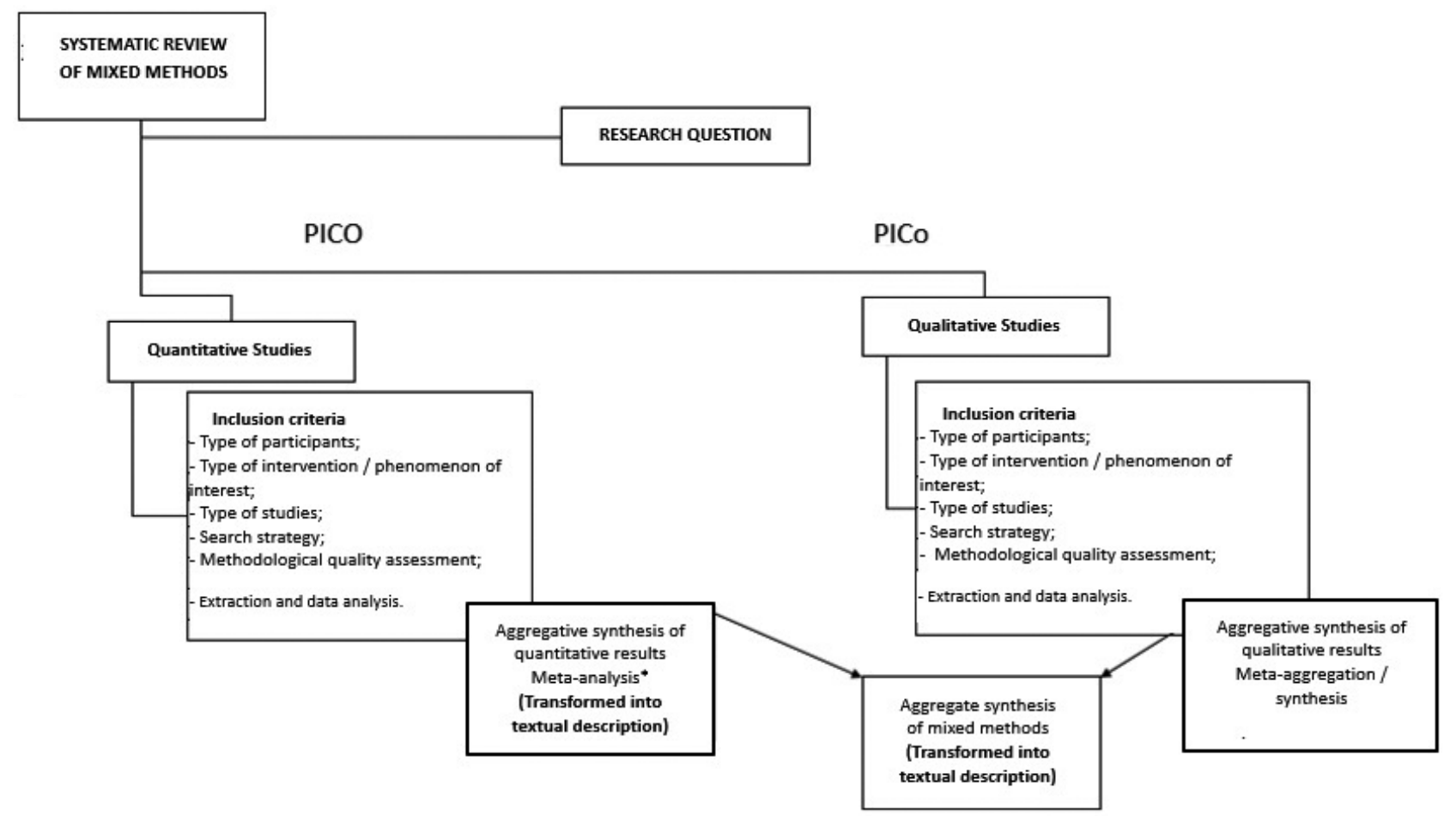

Figure 1 - Representation of the development configuration of Systematic Review of Mixed Methods.

Source: adapted from JBI, $2014 .{ }^{4}$

developed in three levels: level 1 - classification according to the quality of the study; level 2 - grouping of meanings and creation of categories; level 3 - accomplishment of the meta-synthesis to produce a single synthesis. For the synthesis of the quantitative studies, it is necessary that the analysis process of the studies is carried out separately, using, whenever possible, meta-analysis. However, numerical results are transformed into statements. At the end of the two syntheses, we aggregate them for the interpretation of the findings associated with theories, comparisons, and contrasts of their results, from the context investigated. In both quantitative and qualitative studies, when a metasynthesis and meta-analysis cannot be performed, a narrative synthesis can be performed (Figure 1). ${ }^{4}$

The final synthesis of the Systematic Review of Mixed Methods will be configured by converting all numerical results into statements. The themes generated in the qualitative synthesis represent the aggregation or the development of a theoretical framework, a set of recommendations or conclusions or, also, an analysis of the ways that may be of evidence for the practice. The discussion process will guide a line of argument based on the findings and the phenomenon of interest, as well as its impact on the objectives identified in the protocol. ${ }^{4}$

\section{The assessment of the quality of evidence}

This step aims to understand the quality of the evidence, as this is a decisive aspect for the development of EBP. The classifications of evidence may have several names, such as type or strength of evidence, level of evidence and level of the study that gave rise to it, value of evidence or hierarchy of evidence. The classification of the evidence guides the elaboration of the degrees of recommendation for a certain conduct, in order to determine the confidence in the use of its results and to strengthen the conclusions that will generate the state of the current knowledge of the researched subject. ${ }^{13}$

The JBI has developed its own methodology for assessing the level of evidence and grade of recommendation, where the levels of evidence for therapy/interventions, prognosis and diagnosis are 
designed to align with the GRADE system (Grading of Recommendations Assessment, Development and Evaluation), based on the study design. However, the great difference between the traditional GRADE approach and the JBI model lies in the analysis of qualitative studies, through clear definitions for the selection of qualitative studies of high quality. Regarding the level of evidence of the results of the studies, the classification of the FAME scale (Feasibility, Appropriateness, Meaningfulness, Effectiveness). This scale made it possible to evaluate the studies considering: the viability of the intervention according to the cultural, physical and financial conditions of a given environment; the suitability for conditions that allow the application of the results of the research to a certain situation; evaluation of the positive experience by the subjects about a given intervention through personal meaning, opinions, values, thoughts, beliefs and the effect of the intervention, when used appropriately, according to the purpose and level reached. ${ }^{4}$

For the degree of recommendation, the JBI adopts a binary system, with strong or weak recommendation, that must be classified according to FAME scale and level of evidence. A recommendation is strong for a given health management strategy and is used when there is evidence of adequate quality for its use; when benefit or no impact on the use of resources; or when the patient's values, preferences, and experience are considered. When using a strong recommendation, use the active voice, using phrases like "we recommend / health professionals should". On the other hand, a recommendation is considered weak for a particular health management strategy when the desirable effects seem to compensate for the undesirable effects of the strategy; where there is evidence to support its use, although it may not be of high quality; when there is benefit, no impact or minimal impact on the use of resources or values and preferences; and when the patient's experience may or may not have been taken into account. In this case, phrases like "we suggest / professionals can / can be used" are used for recommendations. ${ }^{4}$

The use of JBI's level of evidence and degree of recommendation is adequate for nursing research. This method encompasses the analysis of qualitative studies and enables the evaluation of the feasibility and adequacy of the intervention in a given context.

\section{CONCLUSION}

Nursing predominates in interpersonal relationships and health and illness care, focusing on human interaction and deepening individual experiences. Therefore, it is necessary to search for new research methodologies in Nursing based on Evidences that encompass the different contexts experienced by the nurse. The purpose of this study was to reflect on the methodology proposed by the JBI for Systematic Review of Mixed Methods, since it is an international research, development and organization body specializing in EBP in nursing, and for its interest in the context of cost-effective care, as well as the preferences of patients, caregivers, and health care providers.

Through this article, it is noticed that the Systematic Review of Mixed Methods is a research method that aligns with the characteristics of nursing. It allows a more complex and integrated analysis of the different aspects of care without overlapping degrees of importance such as: the feasibility of an activity or intervention, the adequacy of the intervention in a given context, the significance of the intervention for the patient and the effectiveness of the intervention. Their conclusions bring the possibility of incorporating scientific evidence into clinical nursing practice, increasing the focus of care and bringing benefits to patients. 


\section{REFERENCES}

1. Ministério da Saúde (BR). Secretaria de Ciência, Tecnologia e Insumos Estratégicos. Departamento de Ciência e Tecnologia. Diretrizes metodológicas: elaboração de revisão sistemática e metanálise de ensaios clínicos randomizados. Brasília (DF):MS;2012.

2. Sandelowski M, Voils Cl, Leeman J, Crandell JL. Mapping the Mixed Methods-Mixed Research Synthesis Terrain. J Mix Methods Res [Internet]. 2012 Oct [cited 2017 Mar 30];6(4):317-31. Available from https://doi.org/10.1177/1558689811427913

3. Sandelowiski M. Unmixing Mixed-Methods Research. Res Nurs Health [Internet]. 2014 Nov [cited 2017 Mar 30]; 37(1):3-8. Available from: https://doi.org/10.1002/nur.21570

4. Joanna Briggs Institute. Reviewers' Manual-Methodology for JBI Mixed Methods Systematic Reviews. [Internet]. Adelaide: JBI, 2014 [cited 2016 Abr 02]. Available from: http://joannabriggs. org/assets/docs/sumari/ReviewersManual_Mixed-Methods-Review-Methods-2014-ch1.pdf

5. Ribeiro JP. Revisão de investigação e evidência. Psicol Saúde Doenças [Internet] 2014 [cited 2016 Mar 28];15(3):671-82. Available from: http://dx.doi.org/10.15309/14psd150309

6. Noblit GW, Hare RD. Meta-Ethnography: synthesizing qualitative studies. Londres, UK: Sage; 1988. Available from: https://doi.org/10.4135/9781412985000

7. Campbell R, Pound P, Pope C, Britten N, Pill R, Morgan M et al. Evaluating meta-ethnography: a synthesis of qualitative research on lay experiences of diabetes and diabetes care. Soc Sci Med [Internet]. 2003 Feb [cited 2017 Mar 30];65:671-84. Available from: https://doi.org/10.1016/ S0277-9536(02)00064-3

8. Gough D. Qualitative and mixed methods in systematic reviews. Syst Rev [Internet]. 2015 [cited 2017 Mar 30];4:181. Available from: https://doi.org/10.1186/s13643-015-0151-y

9. Collier R. Dr. David Sackett, A giant among giants (1934-2015). CMAJ [Internet]. 2015 Jun [cited 2016 Mar 30];187(9):640-1. Available from: https://dx.doi.org/10.1503\%2Fcmaj.109-5072

10. Sackett DL, Rosenberg WMC, Gray JAM, Haynes RB, Richardson WS. Evidence based medicine: what it is and what it isn't. BMJ [Internet]. 1996 Jan [cited 2016 Mar 30];312:71-2. Available from: https://doi.org/10.1136/bmj.312.7023.71

11. Padilha MI. Pesquisa translacional: qual a importância para a prática da enfermagem? Texto Contexto Enferm [Internet]. 2011 Jul [cited 2017 Mar 30];20(3):419-20. Available from: http:// www.scielo.br/pdf/tce/v20n3/01.pdf

12. Sackett DL, Strauss SE, Richardson WS, Rosemberg W, Haynes RB. Evidence-Based medicine:how to practice and teach EBM. Edinburgh(UK): Churchill Livingstone; 2010.

13. Lacerda RA, Nunes BK, Batista AO, Egry EY, Graziano KU, Angelo M et al. Práticas baseadas em evidências publicadas no Brasil: identificação e análise de suas vertentes e abordagens metodológicas. Rev Esc Enferm USP [Internet]. 2011 Jun [cited 2017 Feb 07];45(3):777-86. Available from: http://dx.doi.org/10.1590/S0080-62342011000300033.

14. Pearson A, Jordan Z, Munn Z. Translational science and evidence-based healthcare: a clarification and reconceptualization of how knowledge is generated and used in healthcare. Nurs Res Pract [Internet]. 2012 Feb [cited 2017 Mar 30];2012:792519. Available from: https:// doi.org/10.1155/2012/792519

15. Cochrane Collaboration. Cochrane Handbook for Systematic Reviews of Interventions. Version 5.1.0. [Internet]. 2011 [cited 2017 Mar 30]; Available from: http://handbook.cochrane.org/

16. Gillman L, Adams J, Kovac R, Kilcullen A, House A, Doyle C. Strategies to promote coping and resilience in oncology and palliative care nurses caring for adult patients with malignancy: a comprehensive systematic review. JBI Database System Rev Implement Rep [Internet]. 
2015 Jun 12 [cited 2017 Mar 30];13(5):131-204. Available from: https://www.ncbi.nlm.nih.gov/ pubmed/26455609

17. Alan P, White H, Bath-Hextall F, Salmond S, Apostolo J, Kirkpatrick P. A mixed-methods approach to systematic reviews. Int J Evid Based Healthc [Internet]. 2015 Sep [cited 2017 Mar 30];13(3):12131. Available from: https://www.ncbi.nlm.nih.gov/pubmed/26196082

18. Sandelowski M, Voils Cl, Barroso. Defining and Designing Mixed Research Synthesis Studies. Res Sch [Internet]. 2006 Mar [cited 2017 Mar 30];13(1):29. Available from: https://www.ncbi.nlm. nih.gov/pmc/articles/PMC2809982/

19. Robert CP. On the relevance of the Bayesian approach to statistics review of economic analysis [Internet]. 2010 [cited 2017 Mar 30];2(2010):139-52. Available from: https://core.ac.uk/download/ pdf/6554327.pdf

20. Pearson A. Meta-aggregation: emergence of the "missing" piece in qualitative synthesis. JBI Database System Rev Implement Rep [Internet]. 2016 [cited 2017 Mar 30];14(12):1-3. Available from: https://doi.org/10.11124/JBISRIR-2016-003257

21. Crandell JL, Voils $\mathrm{Cl}$, Chang $\mathrm{Y}$, Sandelowski M. Bayesian data augmentation methods for the synthesis of qualitative and quantitative research findings. Qual Quant [Internet]. $2011 \mathrm{Apr}$ [cited 2017 Mar 30];45(3):653-69. Available from: https://doi.org/10.1007/s11135-010-9375-z 


\section{NOTES}

\section{CONTRIBUTION OF AUTHORITY}

Study design: Cardoso V, Waterkemper R

Data analysis and interpretation: Cardoso V, Waterkemper R

Writing and / or critical review of content: Cardoso V, Trevisan I, Cicolella DA, Waterkemper R

Review and final approval of the final version: Cardoso V, Trevisan I, Cicolella DA, Waterkemper R

CONFLICT OF INTEREST

No any conflict of interest.

\section{HISTORICAL}

Received: April 10, 2017.

Approved: August 10, 2017.

\section{CORRESPONDENCE AUTHOR}

Roberta Waterkemper

robswater@ufcspa.edu.br 